\title{
Introduction: showcasing the diversity of women's entrepreneurship research
}

\section{Karen D. Hughes and Jennifer E. Jennings}

\section{RESPONDING TO THE CALL FOR DIVERSITY}

Just as it is difficult to deny the impact that female entrepreneurs are having on the world economy, so too is it hard to overlook their diversity. Data from the Global Entrepreneurship Monitor (GEM), for example, reveal striking differences in the proportion of women engaged in entrepreneurial activity around the world, with rates lower than 4 per cent in countries such as Belgium and France yet higher than 38 per cent in countries such as Thailand and Peru (Allen et al., 2007). The GEM data also reveal considerable variability in the motivations, backgrounds and perceptions of women who pursue entrepreneurship - even among those in the same geographic region. Indeed, out of all the possible themes to emphasize within the conclusion of their report, Allen and her colleagues chose to highlight the 'diversity of circumstances and perspectives' that characterize female entrepreneurs the world over (2007: 40; see also Minniti, et al., 2005).

Other researchers have not only remarked upon the heterogeneity of women entrepreneurs but also called for greater appreciation of their diversity by scholars and policy-makers alike. Each of us, for instance, has highlighted this theme in previous, independently conducted research on self-employed and business-owning women in Canada. Noting that 'it is diversity that most characterizes the female face of enterprise', Hughes argued that academic scholars and public policy analysts must work towards a richer, more nuanced, understanding of women's entrepreneurial endeavours (2005: 194). Similarly, Jennings and Provorny Cash remarked:

To date, much of our knowledge derives from comparisons between the 'average' male and female entrepreneur. In order to best help female entrepreneurs, we need to identify and understand any systematic differences between them. Otherwise, we risk the danger that our policy initiatives will be based upon a theoretical 'prototypical' female entrepreneur that, in reality, does not capture the essence of many women business owners at all. (2006: 83; emphasis in original) 
We are not the only ones to articulate such a call. In their introduction to the Entrepreneurship Theory and Practice special issues, de Bruin et al. challenged researchers to 'capture the heterogeneity of what constitutes women's entrepreneurship' (2006: 590), arguing that 'comparisons between groups of women will allow us to fully understand gendered processes and gendered attributes in new ventures' (2007: 329). Similarly, scholars of gender and organizations more broadly have noted the value of an 'intersectional' approach that can illuminate the diversity among women (Browne and Misra, 2003; Holvino, 2010; McCall, 2005). Encouragingly, there are signs that this theme is being heard, understood and appreciated within the policy realm. An analyst with Industry Canada, for example, concluded his recent report with the remark that 'investigating female business owners as a homogeneous group will likely mask' their varying challenges, needs and concerns (Jung, 2010: 19).

In keeping with the spirit of such calls, this book celebrates the variety of women's entrepreneurship research being conducted by scholars affiliated with the DIANA International Research Network. Founded in 1999 by Professors Candida Brush, Nancy Carter, Elizabeth Gatewood, Patricia Greene and Myra Hart, this open and collaborative network comprises researchers around the world who are committed to advancing knowledge about female entrepreneurs. Since its inception, the number of countries represented by participants in the network's bi-annual conference has steadily increased. So, too, has the number of regions in which their studies are situated. At the most recent conference that was held in Banff, Canada, in August 2010, researchers from over 20 countries exchanged knowledge about women engaged in entrepreneurship within almost every continent. This edited volume - the third in the Diana International series - represents just a sample of the eclectic, informative and thought-provoking work being produced by those affiliated with this global research network.

\section{PORTRAYING THE HETEROGENEITY IN CURRENT RESEARCH}

\section{Overarching Tripartite Structure}

To help structure the diverse studies included in this collection, and lend coherence to the overall volume, our organizing framework draws upon three currents salient within recent discourse about how to incorporate heterogeneity within future research. One such current calls for greater 
attention to contextual factors - a theme emphasized not only by women's entrepreneurship scholars such as Ahl (2006) but also by general entrepreneurship scholars such as Zahra (2007) and broader organizational scholars such as Bamberger (2008; see also Bamberger and Pratt, 2010). Consistent with this call, the first component of our overarching tripartite framework focuses upon the diverse settings in which research on women entrepreneurs is currently being conducted, whether those settings represent entire socio-economic regions, specific national contexts, or certain industrial, institutional or familial contexts.

Another prominent theme emphasizes the importance of adopting different perspectives and asking new questions - especially those that have been silenced within mainstream research on a focal topic to date. In her critique of the women's entrepreneurship literature, for example, Ahl noted that 'the growth argument', in particular, 'is a strong discursive practice [that] allows research to consider certain questions and ignore others' (2006: 602). Extending this argument, Calás et al. (2009) demonstrated the variety of unasked questions worthy of investigation when entrepreneurship, more generally, is viewed from a critical and reflexive standpoint. Within the broader organizational literature, the call for different perspectives is perhaps most evident in a recent Academy of Management Review special issue entitled, 'Where are the new theories of organization?' Consistent with this theme, the second component of our overarching tripartite framework focuses upon the diverse questions currently addressed by women's entrepreneurship scholars around the world.

A final theme commonly emphasized within treatises on advancing scholarship in a focal field focuses upon the importance of utilizing multiple methodologies. Such a theme is evident within recent reviews of the women's entrepreneurship literature, especially with respect to the need for embracing less orthodox methods (for example, Ahl, 2006; de Bruin et al., 2007). Similarly, Neergaard and Ulhøi critiqued the entrepreneurship literature more generally as 'lacking in methodological diversity' even though, rather ironically, 'the entrepreneurial phenomenon itself, in all its complexity and dynamics, invite[s] a methodological toolbox of broad variety' (2007: 1). Intriguingly, within the broader field of organizational studies there is a trend towards greater methodological diversity as well. For instance, Buchanan and Bryman's recent handbook on organizational research methods showcases a wide array of innovative work (2009). As such, the third component of our overarching framework showcases the diverse approaches that the scholars in this volume have collectively adopted within their work on women entrepreneurs. 
Table I.1 Framework for capturing the variety of studies included in the collection

\begin{tabular}{|c|c|c|c|}
\hline & Diverse settings & Diverse questions & Diverse approaches \\
\hline \multirow[t]{2}{*}{ Macro } & $\begin{array}{l}\text { Chapter } 1 \text { : } \\
\text { The effects of } \\
\text { national culture } \\
\text { on female migrant } \\
\text { entrepreneurs in } \\
\text { the UK and the } \\
\text { Netherlands }\end{array}$ & $\begin{array}{l}\text { Chapter 5: } \\
\text { How do welfare } \\
\text { regimes influence } \\
\text { women's } \\
\text { entrepreneurship } \\
\text { around the world? }\end{array}$ & $\begin{array}{l}\text { Chapter 9: } \\
\text { A multi-country } \\
\text { analysis of the } \\
\text { effects of gender } \\
\text { equality on } \\
\text { rates of female } \\
\text { self-employment }\end{array}$ \\
\hline & $\begin{array}{l}\text { Chapter 2: } \\
\text { The impact of policy } \\
\text { initiatives on women- } \\
\text { owned SMEs in } \\
\text { Bangladesh }\end{array}$ & $\begin{array}{l}\text { Chapter 6: } \\
\text { Should women go } \\
\text { into business with } \\
\text { their family partner? }\end{array}$ & $\begin{array}{l}\text { Chapter 10: } \\
\text { A single case study } \\
\text { of copreneurial } \\
\text { roles and identities } \\
\text { within a gendered } \\
\text { industry }\end{array}$ \\
\hline & $\begin{array}{l}\text { Chapter 3: } \\
\text { The influence of } \\
\text { institutions on } \\
\text { academic women } \\
\text { entrepreneurs in } \\
\text { Spain and Scotland }\end{array}$ & $\begin{array}{l}\text { Chapter } 7 \text { : } \\
\text { Are women more } \\
\text { likely to pursue social } \\
\text { and environmental } \\
\text { entrepreneurship? }\end{array}$ & $\begin{array}{l}\text { Chapter 11: } \\
\text { A factor analysis } \\
\text { examining the } \\
\text { nature of women's } \\
\text { entrepreneurial } \\
\text { self-efficacy }\end{array}$ \\
\hline Micro & $\begin{array}{l}\text { Chapter 4: } \\
\text { The effects of money } \\
\text { vs motivations on } \\
\text { the performance of } \\
\text { female-owned firms } \\
\text { in the US }\end{array}$ & $\begin{array}{l}\text { Chapter 8: } \\
\text { Do even highly } \\
\text { accomplished female } \\
\text { entrepreneurs tend to } \\
\text { 'give away success'? }\end{array}$ & $\begin{array}{l}\text { Chapter 12: } \\
\text { A reflexive } \\
\text { approach on } \\
\text { the potential } \\
\text { advantages inherent } \\
\text { in being a female } \\
\text { entrepreneur }\end{array}$ \\
\hline
\end{tabular}

\section{Underlying Multi-level Substructure}

As illustrated in the visual representation of our organizing framework presented in Table I.1, we have further structured the chapters comprising the above-noted major parts according to a macro-to-micro logic. Each of the lead chapters focuses upon a macro-environmental factor relevant to women's entrepreneurship, such as the effects of policies or culture at the national level. The middle chapters draw attention to meso-level influences, such as the intermediaries who provide support to female entrepreneurs or the sectoral, institutional or familial contexts in which they are embedded. 
The final chapter within each part highlights micro-level considerations, such as the resources, motivations and attitudes held by these women.

Structuring the chapters within each section in this manner not only further illustrates the diversity of women's entrepreneurship research currently being conducted by DIANA International scholars, but is also consistent with the multi-level approach advocated within recent overview articles and books on the topic (for example, Brush et al., 2009; 2010; Elam, 2008) as well as within entrepreneurship research in general (for example, Davidsson and Wiklund, 2001; Rindova et al., 2009). Moreover, by starting each part with a macro-oriented chapter, we offer a small step towards addressing the critique that prior work on female entrepreneurs has tended to adopt the individualist focus that permeates the entrepreneurship literature more broadly (Ahl, 2006). Synopses of the individual chapters appear below.

\section{PREVIEWING THE VARIOUS CHAPTERS}

\section{Part I Diverse Settings}

Precisely how different national and industrial contexts shape the nature and trajectory of women's entrepreneurial venturing are questions ripe for exploration, especially given the dramatic expansion of women-led enterprise around the globe (Brush et al., 2010). In our first part we explore a diverse range of settings - from those rarely examined, to those representing more familiar terrain.

In Chapter 1, Anne Humbert and Caroline Essers offer insights into Turkish business women operating in two distinct national contexts: the UK and the Netherlands. Drawing on life history narratives and structuration theory, Humbert and Essers explore how the intersections of gender, ethnicity, citizenship and national context shape women's entrepreneurial identities and daily business practices. Their qualitative study reveals distinct approaches to networking, financing, coaching and entrepreneurial identity work. Speaking to the influence of national context, Humbert and Essers conclude that Turkish women in the Netherlands experience more tensions between their identities as women, migrants and entrepreneurs than those in UK, who are more included within mainstream and Turkish business circles.

In Chapter 2, Salma Zohir and Patricia Greene examine a context where women's entrepreneurial activity has been less frequently studied: Bangladesh. Focusing on small and medium-sized enterprise (SME) financing, they offer a valuable assessment of women-led business, integrating 
existing survey data and primary interview and focus group research with female entrepreneurs and institutional lenders. Despite macro-level policies that have sparked growth and diversity in women's enterprise in the country, significant barriers to financing remain. Zohir and Greene's study suggests intriguing parallels to other national contexts with respect to demand- and supply-side barriers to financing, while also showing how unique aspects of Bangladeshi culture (for example, gender attitudes) carry special ramifications for women seeking financial capital. They conclude their chapter with specific recommendation for policy change.

Broadening the reach of 'diverse settings', Chapter 3 by Mar FuentesFuentes, Sarah Cooper and Ana Bojica consider the intersections between national and industrial contexts, focusing on academic women and female-led 'spin offs' in the university sectors of Scotland (University of Edinburgh) and Spain (University of Granada). Guided by institutional theory, and drawing on in-depth interviews with female academic entrepreneurs and technology transfer officers, the authors trace the competing influence of macro-, meso- and individual factors. Their study highlights the importance of meso-level factors, showing that few women academics engage in commercialization and spin-offs, and that universities need to adopt gender-aware policies and practices that can counteract bias and negative influences from the macro-environment. These insights are critical given the growing role of science, engineering and technology (SET) fields in knowledge-based economies, and the need for female entrepreneurs to flourish there.

Our first section concludes with Chapter 4 by Susan Coleman and Alicia Robb, who examine the links between financial capital, motivations and expectations, and firm performance for male- and female-led firms in the USA. Although the USA is certainly one of most studied settings for women entrepreneurs, this also makes it an ideal setting to explore critical debates about the gender gap in financing and firm performance. Drawing on longitudinal data, and testing hypothesis derived from resource-based theory and motivational theory, Coleman and Robb offer several new insights. In particular, while finding few differences in the performance of male- and female-owned firms after controlling for standard factors, their analysis suggests that gender differences in motivation, start-up capital and a desire for controlled growth may all play a central role in understanding the performance gap.

\section{Part II Diverse Questions}

Writing about research on women, Sandra Harding (1987) famously noted that the questions we ask are as determinative of our knowledge as any 
answers we might discover. Echoing this perspective, recent commentators on the field of women's entrepreneurship research have also noted how certain questions have been amplified, muted or unheard in scholarship to date (Ahl, 2006; Calás et al., 2009). Our second part is therefore dedicated to taking up diverse questions, showcasing both new questions that have not been asked before, as well as familiar questions that are re-framed in fresh, innovative ways.

Beginning at the macro-level of analysis, Chapter 5 by Nicholas Fairclough raises questions about the linkages between institutional and individual levels of analysis, focusing on the specific role that social welfare provision and policy play in shaping women's entrepreneurial activity across nations. Drawing on the 'welfare regimes' framework of political scientist Esping-Andersen, as well as a 'real options' perspective, Fairclough draws on existing research to develop propositions as to how distinct social welfare policy provisions and approaches might shape patterns of women's entrepreneurship with respect to start-up and success; the negotiation of work-family conflict; and the navigation of necessity and opportunity entrepreneurship.

In Chapter 6, Manely Sharifian, Devereaux Jennings and Jennifer Jennings consider an important, but largely unexamined, question: whether women (and men) benefit from going into business with their spouse or significant other. Working from a family embeddedness perspective, and drawing on survey data from small business owners in Western Canada, the authors compare copreneurial and non-copreneurial firms with respect to their satisfaction and performance in both work and family spheres. While their analysis finds no difference in business performance, copreneurs do experience higher family satisfaction. Moreover, intersections between work and family spheres reveals that experiencing greater equity at home (for example, sharing of household tasks) positively influences family satisfaction for copreneurs, but with adverse effects on business performance and satisfaction. The authors conclude by suggesting several new avenues for future research.

New questions are also posed in Chapter 7, which examines interconnections between the rise of women's entrepreneurship and alternative strands of entrepreneurship; in particular, 'social entrepreneurship' and 'ecopreneurship'. Noting that few studies have explored these links, Diana Hechavarria, Amy Ingram, Rachida Justo and Siri Terjesen examine whether female entrepreneurs are more likely than their male peers to emphasize social and environmental value creation as part of their entrepreneurial goals. Drawing on theories of hegemonic masculinity, and utilizing data from the 2009 Global Entrepreneurship Monitor survey 
of 52 countries, the authors find that male entrepreneurs do indeed give greater priority to traditional economic outcomes (for example, profit), while women place more emphasis on social and environmental concerns. Notably this is the case both for actual business practices as well as for desired goals.

Part II concludes with a critical revisiting of familiar questions about women's relationship to achievement and success. In Chapter 8, Mary Riebe utilizes data from online questionnaires with a small group of highly successful women in the USA who have been operating a business for more than five years. Surveying the wide body of psychologically oriented literature from the North American context, Riebe argues that the women in her study do not conform to earlier research findings concerning attributions of success, silencing and recognition, relational approaches and conflict management. Such findings raise questions, Riebe concludes, not only about established scholarship but also about the changing nature, and sophistication, of women's entrepreneurial endeavours.

\section{Part III Diverse Approaches}

In light of the growing methodological plurality of social science research generally, it is not surprising that entrepreneurship research is embracing a much broader array of research approaches. As noted earlier, there is growing awareness that the dynamic and complex nature of entrepreneurial endeavours requires a 'methodological toolbox' that is up to the task (Neergaard and Ulhøi, 2007: 1).

In Chapter 9, Kim Klyver, Suna Løwe Nielsen and Majbritt Rostgaard Evald utilize hierarchical logistic regression to test findings from previous qualitiative studies on the relationship between gender equality at the institutional level and employment choice at the individual level. Building on the observation that existing studies fail to capture the economic, cultural and political contexts in which individual choices occur, the authors merge two comprehensive datasets - the Global Entrepreneurship Monitor and the World Economic Forum's Global Gender Gap index - in order to examine the links between institutional contexts and individual employment patterns in 50 different countries. Results confirm that countries with high levels of institutionalized gender equality have much lower rates of female entrepreneurial activity. Moreover, split-age comparisons suggest that 'family friendly' policies (for example, generous maternity and childcare provisions) have a dampening effect on self-employment for women of child-bearing age.

The value of an interpretist approach is illustrated in Chapter 10, 
where Maura McAdam and Susan Marlow explore how gender is collectively constructed and performed in entrepreneurship. Focusing on a female-dominant sector, and utilizing an in-depth, interview-based case study of a copreneurial au pair business in New Zealand, they explore the reversal of normative gender relations - where a female partner is positioned as the 'publicly visible' leader, while the male partner provides 'behind-the-scenes' support. While on the surface, McAdam and Marlow argue, this business seems to disrupt established gender binaries, a closer reading reveals a reinscription of traditional gender norms, with the male partner controlling influential decisions on financing, growth and strategic management, while his partner offers a reassuring 'feminine face' that meshes with deeply held normative assumptions conflating femininity and care.

Utilizing a factor-analytic approach and adopting a gendered perspective, Chapter 11 by Cristina Díaz García explores the issue of entrepreneurial self-efficacy (ESE); that is, the subjective assessment of one's skills, ability, and knowledge related to business start-up and management. Questioning prior research with respect to gender differences as well as the typical unidimensional conceptualization of ESE, Díaz García draws on Spanish survey data to show that ESE is in fact multidimensional, encompassing decisional, financial and relational components. Equally important, she shows that gender differences in ESE are not as pronounced, or constant, as past research suggests. Contrary to findings of lower ESE for women, Díaz García shows that ESE is context specific, with gender differences in specific facets (for example, decisional, financial and relational) varying by education, business experience, age, growth intentions, as well as location in traditional versus non-traditional sectors.

We conclude our final part with Chapter 12, by Albert James, who offers a reflexive critical essay on the dominant approaches that have been used to frame research on women's entrepreneurial activity. Echoing Ahl's (2006) observations about the 'problem-based' nature of research on women entrepreneurs, James contends that such approaches eclipse questions about the success of women entrepreneurs. His case study of a successful female entrepreneur operating in a male-dominated industry identifies ways in which female identity, experiences and competencies may operate as an 'advantage'. Resonating with current strands of debate within positive psychology (Cameron et al., 2003), James outlines an alternative model of female entrepreneurship - one he contends scholars might use productively to capture and understand the factors and conditions that allow women entrepreneurs to flourish. 


\section{ADVANCING OUR UNDERSTANDING OF THE DIVERSITY OF WOMEN ENTREPRENEURS}

In the same way that the DIANA International Research Network and affiliated conferences have done so much to broaden and enrich knowledge about women's entrepreneurship, it is our hope that this third volume by Elgar contributes empirically, theoretically and methodologically towards a richer, more complete, picture of the diversity embraced within women's entrepreneurial activity around the world. Moreover, in keeping with a 'virtuous cycle' of research (Brush et al., 2010), we hope this volume also offers insights to policies and programmes that seek to support the rich and varied nature of women's entrepreneurial ambitions.

\section{REFERENCES}

Ahl, H. (2006), 'Why research on women entrepreneurs needs new directions', Entrepreneurship Theory and Practice, 30 (5), 595-621.

Allen, I.E., A. Elam, N. Langowitz and M. Dean (2007), '2007 report on women and Entrepreneurship', Global Entrepreneurship Monitor.

Bamberger, P. (2008), 'From the editors: beyond contextualization - using context theories to narrow the micro-macro gap in management research', Academy of Management Journal, 51 (5), 839-46.

Bamberger, P.A. and M.G. Pratt (2010), 'From the editors - moving forward by looking back: reclaiming unconventional research contexts and samples in organizational scholarship', Academy of Management Journal, 53 (4), 665-72.

Browne, I. and J. Misra (2003), 'The intersection of gender and race in the labour market', Annual Review of Sociology, 29, 487-513.

Brush, C.G., A. de Bruin, and F. Welter (2009), 'A gender-aware framework for women's entrepreneurship', International Journal of Gender and Entrepreneurship, 1 (1), 8-24.

Brush, C.G., A. de Bruin, E.J. Gatewood, and C. Henry (2010), 'Introduction: women entrepreneurs and growth', in C.G. Brush, A. de Bruin, E.J. Gatewood, and C. Henry (eds), Women Entrepreneurs and the Global Environment for Growth, Cheltenham, UK and Northampton, MA, USA: Edward Elgar Publishing, pp. 1-18.

Buchanan, D.A. and A. Bryman (2009), 'The organizational research context: properties and implications', in D. Buchanan and A. Bryman (eds), The Sage Handbook of Organizational Research Methods, Thousand Oaks, CA: Sage Publications, pp. 1-18.

Calás, M.B., L. Smircich and K.A. Bourne (2009), 'Extending the boundaries: reframing "Entrepreneurship as Social Change" through feminist perspectives', Academy of Management Review, 34 (3), 552-69.

Cameron, K.S., J.E. Dutton and R.E. Quinn (2003), 'Foundations of positive organizational Scholarship', in K.S. Cameron, J.E. Dutton, and R.E. Quinn 
(eds), Positive Organizational Scholarship: Foundations of a New Discipline, San Francisco, CA. Berrett-Koehler, pp. 3-13.

Davidsson, P. and J. Wiklund (2001), 'Levels of analysis in entrepreneurship research: current research practice and suggestions for the future', Entrepreneurship Theory and Practice, 25 (4), 81-100.

De Bruin, A., C.G. Brush and F. Welter (2006), 'Introduction to the special issue: towards building cumulative knowledge on women's entrepreneurship', Entrepreneurship Theory and Practice, 30 (5), 585-93.

De Bruin, A., C.G. Brush and F. Welter (2007), 'Advancing a framework for coherent research on women's entrepreneurship', Entrepreneurship Theory and Practice, 31 (3), 323-39.

Elam, A.B. (2008), Gender and Entrepreneurship: A Multilevel Theory and Analysis, Cheltenham, UK and Northampton, MA, USA: Edward Elgar Publishing.

Harding, S. (1987), 'Is there a feminist method?', in S. Harding (ed.), Feminism and Methodology, Bloomington, IN: Indiana University Press, pp. 1-14.

Holvino, E. (2010), 'Intersections: the Simultaneity of race, gender, and class in organization studies', Gender, Work and Organization, 17 (3), 248-77.

Hughes, K.D. (2005), Risky Business? Women, Self-Employment and Small Business in Canada, Toronto, ON: University of Toronto Press.

Jennings, J.E. and M. Provorny Cash (2006), 'Women's entrepreneurship in Canada: progress, puzzles and priorities; in C.G. Brush, N.M. Carter, E.J. Gatewood, P.G. Greene and M.M. Hart (eds) Growth Oriented Women Entrepreneurs and Their Businesses: A Global Research Perspective, Cheltenham, UK and Northampton, MA, USA: Edward Elgar Publishing, pp. 53-87.

Jung, O. (2010), 'Small business financing profiles: women entrepreneurs', $S M E$ Financing Data Initiative, Small Business and Tourism Branch, Industry Canada.

McCall, L. (2005), 'The complexity of intersectionality', Signs: Journal of Women in Culture and Society, 30 (3), 1772-801.

Minniti, M., I.E. Allen and N. Langowitz (2005), '2005 report on women and entrepreneurship', Global Entrepreneurship Monitor.

Neergaard, H. and J. Parl Ulhøi (2007), 'Introduction', in H. Neergaard and J. Parl Ulhoi (eds), Handbook of Qualitative Research Methods in Entrepreneurship Research, Cheltenham, UK and Northampton, MA, USA: Edward Elgar Publishing, pp. 1-14.

Rindova, V., D. Barry and D.J Ketchen Jr (2009), 'Entrepreneuring as emancipation', Academy of Management Review, 34 (3), 477-91.

Zahra, S.A. (2007), 'Contextualizing theory building in entrepreneurship research', Journal of Business Venturing, 22, 443-52. 
Karen D. Hughes and Jennifer E. Jennings - 9781849804752 Downloaded from PubFactory at 04/26/2023 12:32:10PM 